\title{
SNP mapping of QTL affecting growth and fatness on chicken GGA1
}

\author{
Yousheng RAO ${ }^{\mathrm{a}, \mathrm{b}}, \mathrm{Xu}$ SHEN $^{\mathrm{a}}$, Mengna XIA ${ }^{\mathrm{a}}$, Chenglong LUO ${ }^{\mathrm{a}}$, \\ Qinghua NIE ${ }^{\mathrm{a}}$, Dexiang ZHANG ${ }^{\mathrm{a}}$, Xiquan Zhang ${ }^{\mathrm{a} *}$ \\ a Department of Animal Genetics, Breeding and Reproduction, College of Animal Science, \\ South China Agricultural University, Guangzhou 510642, Guangdong, China \\ ${ }^{\mathrm{b}}$ College of Science, Jiangxi Educational Institute, Nanchang 330029, Jiangxi, China
}

(Received 28 August 2006; accepted 23 April 2007)

\begin{abstract}
An F2 chicken population was established from a crossbreeding between a Xinghua line and a White Recessive Rock line. A total of 502 F2 chickens in 17 full-sib families from six hatches was obtained, and phenotypic data of 488 individuals were available for analysis. A total of 46 SNP on GGA1 was initially selected based on the average physical distance using the dbSNP database of NCBI. After the polymorphism levels in all F0 individuals (26 individuals) and part of the F1 individuals (22 individuals) were verified, 30 informative SNP were potentially available to genotype all F2 individuals. The linkage map was constructed using Cri-Map. Interval mapping QTL analyses were carried out. QTL for body weight (BW) of $35 \mathrm{~d}$ and $42 \mathrm{~d}, 49 \mathrm{~d}$ and $70 \mathrm{~d}$ were identified on GGA1 at 351-353 cM and $360 \mathrm{cM}$, respectively. QTL for abdominal fat weight was on GGA1 at $205 \mathrm{cM}$, and for abdominal fat rate at $221 \mathrm{cM}$. Two novel QTL for fat thickness under skin and fat width were detected at $265 \mathrm{cM}$ and $72 \mathrm{cM}$, respectively.
\end{abstract}

QTL / chicken / growth / fatness / single nucleotide polymorphisms

\section{INTRODUCTION}

A number of tools for genome analyses developed during the last ten years has allowed the identification of the genes and gene polymorphisms controlling complex traits. This has opened perspectives for predictive medicine in humans and marker-assisted selection (MAS) in plants and animals of economic interest $[12,13,16,18]$. Understanding the QTL regulating economically important traits can increase the response of breeding programs, especially for those that are difficult to improve by traditional selection. As an economical animal and a model animal, QTL study in the chicken has been widely conducted and great

* Corresponding author: xqzhang@ @scau.edu.cn 
advances have been achieved. To date, more than 600 QTL have been identified in the chicken using genome scan with microsatellites [25]. The chicken genome comprises 39 pairs of chromosomes, which are divided into eight pairs of cytologically distinct chromosomes 1-8 (macrochromosomes) along with Z and $\mathrm{W}$ sex chromosomes and 30 pairs of microchromosomes. GGA1 is the largest, corresponding to $14.9 \%$ of the entire genome [6,9]. More QTL affecting body weight (BW), growth, feed intake, and weights of breast muscle, thighs, drums, wings and fat deposition have been detected on this chromosome.

Until recently, QTL mapping in chickens was performed mainly by microsatellite linkage analyses. Single nucleotide polymorphisms (SNP) are the most common source of genetic variations in populations. Advances in genome sequencing have led to the discovery of millions of SNP in the chicken genome [26]. Many studies in other species indicated that using the SNP marker is efficient in QTL mapping [4, 14, 17].

In the present study, thirty informative SNP were used to genotype all individuals in an F2 full-sib chicken population established from a crossing between Xinghua (XH) and White Recessive Rock (WRR) chickens. Interval mapping QTL analyses were used to identify QTL associated with growth and fat traits.

\section{MATERIALS AND METHODS}

\subsection{Experimental population}

Xinghua and White Recessive Rock lines were selected for crossing. The White Recessive Rock is a fast growing broiler line that has been bred as a meat type. The Xinghua chicken is a Chinese native breed with slow growth, lower reproduction and favourable meat quality. Both were reared at the Guangdong Wens Foodstuff Ltd Company, China, as a closed population. Nine females and nine males from each line were selected for mating on the basis of consistent egg laying and semen production. Each male was paired with a female from the other line. Two each of the XH $\left(\sigma^{\prime \prime}\right) \times$ WRR $(q)$ and WRR $\left(\sigma^{\prime \prime}\right) \times \mathrm{XH}$ (o) mating were selected on the basis of satisfactory egg and semen yields to create the F1 generation. At 30 wk of age, 17 F1 males and 17 F1 females were selected to produce the F2 generation. An equal number of spare males and females were kept as replacements for any loss. Each male was mated to a female of the same cross from the alternative family. A total of $502 \mathrm{~F} 2$ chickens in 17 full-sib families from six hatches were obtained at two-weekly intervals, and the birds were reared for trait measurement. 


\subsection{Observations}

BW at $7,14,21,28,35,42,49,56,63,70,77$, and $84 \mathrm{~d}$ of age were recorded. All F2 chickens were slaughtered at $90 \mathrm{~d}$ of age, and fat thickness under skin, fat width, abdominal fat weight, and abdominal fat rate were recorded. Fat width was measured between the leg and breast muscles by vernier caliper. Abdominal fat rate was defined as the abdominal fat weight divided by carcass weight. BW gains per day at $0-4$ wk of age (BWG1) and at 5-8 wk of age (BWG2) were defined as BW gain, after being adjusted by the hatch effect, divided by the number of days.

\subsection{SNP selection and genotyping}

Based on the average physical distance, a total of 46 SNP on GGA1 were initially selected from the dbSNP database of the National Center for Biotechnology Information (NCBI). Thirty informative SNP were potentially available for the genotyping of all F2 individuals, after their polymorphism levels in all F0 individuals (26 individuals) and part of the F1 individuals (22 individuals) were verified. Amongst all 30 SNP, rs15397920 did not follow Mendel Laws, and the polymorphism level of rs14937017 was low in the F2 family. After ruling out these two SNP, 28 informative SNP were available for analysis. In the F2, a genetic map was obtained using the CRI-MAP linkage programme [5]. The functions FLIPS and FIXED were used to evaluate the order of markers along the chromosome and to estimate the map distance between markers. rs1384934 4(M4) and rs15551556 (M28) could not be assigned to the linkage group and were therefore excluded from the QTL analysis. The average marker interval was $21.4 \mathrm{cM}$, and the average polymorphic information content was 0.3324 (range $0.0997-0.5642$ ). Figure 1 shows the linkage phase of 26 SNP on GGA1.

Based on the sequences provided by NCBI, proper PCR primers for amplifying each SNP were designed (Tab. I). The $25 \mu \mathrm{L}$ PCR reaction mixture contained $50 \mathrm{ng}$ of chicken genomic DNA, 1 X PCR buffer, 12.5 pmol of each primer, $100 \mu \mathrm{M}$ dNTP (each), $1.5 \mathrm{mM} \mathrm{MgCl}_{2}$ and $1.0 \mathrm{U}$ Taq DNA polymerase (all reagents were from the Sangon Biological Engineering Technology Company; Shanghai, China). The PCR conditions were $3 \mathrm{~min}$ at $94{ }^{\circ} \mathrm{C}$, followed by 35 cycles of $30 \mathrm{~s}$ at $94{ }^{\circ} \mathrm{C}, 45 \mathrm{~s}$ at an annealing temperature (ranged from $55^{\circ} \mathrm{C}$ to $62^{\circ} \mathrm{C}$ according to each primer), $1 \mathrm{~min}$ at $72{ }^{\circ} \mathrm{C}$, and a final extension of $5 \mathrm{~min}$ at $72{ }^{\circ} \mathrm{C}$ in a Mastercycler gradient (Eppendorf Limited, Hamburg, Germany). The PCR products were analysed on a $1 \%$ agarose gel to assess 


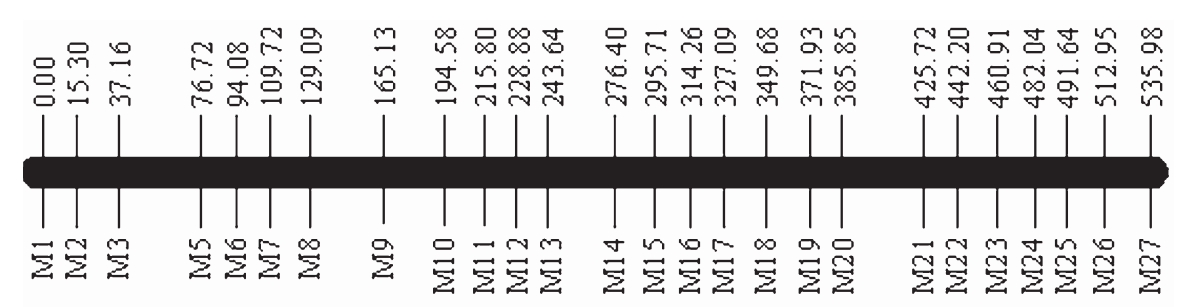

Figure 1. The linkage phase of 26 SNP on GGA1. M1-M27 represents 26 SNP respectively. M4 and M28 could not be assigned to this linkage group. The genetic distance (cM) between markers was estimated by CRI-MAP.

the correct size and quality of the fragments. The RFLP method was utilized in genotyping. The reaction mixture contained $4.0 \mu \mathrm{L}$ PCR products, $0.5 \mu \mathrm{L}$ restriction endonucleases, $1.0 \mu \mathrm{L} 10 \mathrm{X}$ PCR buffer, $4.5 \mu \mathrm{L}$ deionised water. Digestion was carried out at $37{ }^{\circ} \mathrm{C}$ overnight. Restriction patterns were visualized by electrophoresis of the digestion product in a 2-3\% agarose gel stained with ethidium bromide. Table II shows various restriction endonucleases used in each SNP genotyping.

\subsection{QTL analyses}

The QTL mapping method proposed by Haley et al. [7] was implemented using QTL Express software [19]. A linear model for the additive and dominant effects of a QTL at a given position was analysed by least squares for each trait. The additive effect was defined as half the difference between the two homozygotes and the dominant effect as the difference between the means of the heterozygotes and homozygotes. Phenotypic data from the 17 full-sib families were adjusted for hatch effect and the residuals were used in the QTL analyses. The statistical model included family and sex as fixed effects. In the analysis of abdominal fat weight, the fat thickness under skin and the fat width, a covariate-carcass weight included in the statistical model as another fixed effect. When the analysis demonstrated the existence of one QTL for any trait, the presence of two or more QTL was also tested.

\subsection{Significance thresholds and confidence intervals}

Significance threshold analyses were conducted using a permutation test [3]. A total of 10000 permutations were computed to determine the empirical distribution of the statistical test under the null hypothesis of no QTL associated 
Table I. PCR primers for the SNP amplification.

\begin{tabular}{|c|c|c|c|c|c|c|}
\hline $\begin{array}{l}\text { Marker } \\
\text { no. }\end{array}$ & SNP & Variations & Primer $\left(5^{\prime}-3^{\prime}\right)$ & $\begin{array}{l}\text { Annealing } \\
\mathrm{T}\left({ }^{\circ} \mathrm{C}\right)\end{array}$ & $\begin{array}{l}\text { Product } \\
\text { length } \\
\text { (bp) }\end{array}$ & $\begin{array}{l}\text { Position } \\
\text { of SNP }\end{array}$ \\
\hline M1 & rs 15197960 & $\mathrm{G} / \mathrm{T}$ & $\begin{array}{l}\text { TGCAACACAAGATGCTTTCC } \\
\text { CATGGATGCTTTCAGCTTCA }\end{array}$ & 56 & 595 & 131 \\
\hline M2 & rs 13835792 & $\mathrm{~T} / \mathrm{C}$ & $\begin{array}{l}\text { TGGGCAGGTAGAGAGCTGTT } \\
\text { CTGCTTTTCCCCTTTCTCCT }\end{array}$ & 58.5 & 481 & 182 \\
\hline M3 & rs 15217588 & $\mathrm{~A} / \mathrm{G}$ & $\begin{array}{l}\text { GGGGGAAGACTGCTGCTTAT } \\
\text { ATGCCAAACCACCATTGACT }\end{array}$ & 55 & 487 & 156 \\
\hline M4 & rs 13849344 & $\mathrm{~A} / \mathrm{G}$ & $\begin{array}{l}\text { AGGGCTGACAGCTGGTTTTA } \\
\text { ACTTCCAACAGCCCATTCTG }\end{array}$ & 60 & 509 & 104 \\
\hline M5 & rs 15245077 & $\mathrm{~T} / \mathrm{C}$ & $\begin{array}{l}\text { CTGGCTGCAGGAGAGTAAGC } \\
\text { AAGCTGCCAAACAAAACCAG }\end{array}$ & 60 & 489 & 207 \\
\hline M6 & rs 13651060 & $\mathrm{~A} / \mathrm{G}$ & $\begin{array}{l}\text { CTGCTTGCAGACCTCTAGGC } \\
\text { ATACAGGCCAAGCACAGGAA }\end{array}$ & 62 & 439 & 115 \\
\hline M7 & rs 15261060 & $\mathrm{G} / \mathrm{T}$ & $\begin{array}{l}\text { CTTCCCACCAACGTTCTGTT } \\
\text { CCAAAGCTCTGAAAGGCAAG }\end{array}$ & 58 & 593 & 238 \\
\hline M8 & rs 15279778 & $\mathrm{~T} / \mathrm{C}$ & $\begin{array}{l}\text { AATTCATCCCTCCAGCACAG } \\
\text { CTCTCTGCATGCCTTCACTG }\end{array}$ & 56 & 442 & 79 \\
\hline M9 & rs 14837036 & $\mathrm{~A} / \mathrm{G}$ & $\begin{array}{l}\text { ATCCGTGGTTTGGTATTGGA } \\
\text { CCACTTTGCTGCAGTCGTTA }\end{array}$ & 56 & 561 & 405 \\
\hline M10 & rs 15310568 & $\mathrm{~T} / \mathrm{C}$ & $\begin{array}{l}\text { CACCCAAACAGTCCCATTTT } \\
\text { ATTTGCCATGCAGCTTCTTT }\end{array}$ & 56 & 439 & 116 \\
\hline M11 & rs 14848790 & $\mathrm{~T} / \mathrm{C}$ & $\begin{array}{l}\text { CCAGCAGTGTTCTCACCTCA } \\
\text { CTGGATGATCCTGTGGGTCT }\end{array}$ & 60 & 645 & 128 \\
\hline M12 & rs 13896190 & $\mathrm{~A} / \mathrm{G}$ & $\begin{array}{l}\text { TCAGGACCGTGGAGTTTTTC } \\
\text { CCAGCTGAGACAGTTGGACA }\end{array}$ & 60 & 570 & 236 \\
\hline M13 & rs 15343813 & $\mathrm{C} / \mathrm{T}$ & $\begin{array}{l}\text { GTCCAAATTCCCCCAGAGAT } \\
\text { CGGTTGGACTTGGTGATCTT }\end{array}$ & 60 & 558 & 93 \\
\hline M14 & rs 15361441 & $\mathrm{~T} / \mathrm{C}$ & $\begin{array}{l}\text { CAATGGAACAGCCTTGAGTG } \\
\text { CCAGACTTTGACATGCTGGA }\end{array}$ & 55.8 & 557 & 77 \\
\hline M15 & rs 14870625 & $\mathrm{~A} / \mathrm{G}$ & $\begin{array}{l}\text { AATCCCTCGTTCATGATGGT } \\
\text { TAAGCTAGCAGGGCAGTCGT }\end{array}$ & 55 & 534 & 289 \\
\hline M16 & rs 15389943 & $\mathrm{~A} / \mathrm{G}$ & $\begin{array}{l}\text { GCTCAGTTTTGGACCTGCTC } \\
\text { GGCTTCCTCTGCACAACTTC }\end{array}$ & 56 & 557 & 189 \\
\hline M17 & rs 15397270 & $\mathrm{G} / \mathrm{T}$ & $\begin{array}{l}\text { TGTCCGGAAGAGAAGAGGAA } \\
\text { AGCCTGGTTCCATGACAAAC }\end{array}$ & 60 & 400 & 285 \\
\hline M18 & rs 14884316 & $\mathrm{~A} / \mathrm{G}$ & $\begin{array}{l}\text { GTGAGCTTCTGTGGTGCAAA } \\
\text { CGAGAACCACTCCCATCTGT }\end{array}$ & 62 & 468 & 58 \\
\hline M19 & rs 14889388 & $\mathrm{~A} / \mathrm{G}$ & $\begin{array}{l}\text { TGCATGGAGACAACTGGGTA } \\
\text { GGGCTCCTGACGTGGTATTA }\end{array}$ & 56 & 518 & 121 \\
\hline M20 & rs 14893213 & $\mathrm{G} / \mathrm{C}$ & $\begin{array}{l}\text { TAGCTGCAGGCGTACAAAGA } \\
\text { CCGTGCCCTGTACCTGTAGT }\end{array}$ & 56 & 387 & 175 \\
\hline M21 & rs 15462582 & $\mathrm{~T} / \mathrm{C}$ & $\begin{array}{l}\text { AGGCTGAACAGTCCCAGCTA } \\
\text { ATATGGGTGTGTGGCCTTGT }\end{array}$ & 62 & 597 & 115 \\
\hline M22 & rs 15468665 & $\mathrm{~T} / \mathrm{C}$ & $\begin{array}{l}\text { AAGAAAAGCCGTGTTCTGGA } \\
\text { CACTCAGGGCTGTGTCTTGA }\end{array}$ & 60 & 393 & 81 \\
\hline M23 & rs 15481358 & $\mathrm{C} / \mathrm{G}$ & $\begin{array}{l}\text { GAGTGTCCCTCTCCCTTTCC } \\
\text { GCTTTTAGCCCACTGTGCAT }\end{array}$ & 56 & 432 & 214 \\
\hline M24 & rs 14915286 & $\mathrm{~A} / \mathrm{G}$ & $\begin{array}{l}\text { TAGCTTTGGCATCCTCACCT } \\
\text { AGAAATGTGGATGGGAGCAC }\end{array}$ & 56.7 & 522 & 264 \\
\hline
\end{tabular}


Table I. Continued.

\begin{tabular}{ccccccc}
\hline $\begin{array}{c}\text { Marker } \\
\text { no. }\end{array}$ & SNP & Variations & Primer $\left(5^{\prime}-3^{\prime}\right)$ & $\begin{array}{c}\text { Annealing } \\
\mathrm{T}\left({ }^{\circ} \mathrm{C}\right)\end{array}$ & $\begin{array}{c}\text { Product } \\
\text { length } \\
(\mathrm{bp})\end{array}$ & \\
\hline M25 & rs 15503250 & A/G & & AGTGCCTGTGAGGACAAACC \\
M26 & rs15520693 A/G & $\begin{array}{l}\text { CCAATCCACCAAAGATGTCC } \\
\text { GAGAGAGCCTCCGCTAATGA }\end{array}$ & 60 & 464 & 288 \\
M27 & rs15538603 A/G & $\begin{array}{l}\text { GGACAATCTCCTCCCTCTCC } \\
\text { ATGTACTGGGACTGCCTTGG }\end{array}$ & 60 & 598 & 102 \\
M28 & rs15551556 A/T & $\begin{array}{l}\text { TGCCACTTACACAGGTGCTC } \\
\text { GTGGGCAAGCTGATGATTT } \\
\text { TGTACCAGTCCCCTCACACA }\end{array}$ & 62 & 541 & 248 \\
\hline
\end{tabular}

with the part of the genome under study. Three significance levels were used: suggestive, 5\% and 1\% genome-wide [13]. An approximate confidence interval for the localization of each of the significant and suggestive QTL was obtained using the bootstrap technique $[13,24]$ with a total of 10000 samplings.

\section{RESULTS}

\subsection{QTL for growth traits}

The overall means and standard deviations (SD) of 14 growth traits are presented in Table III. Four QTL related to growth were identified. QTL for $35 \mathrm{~d} \mathrm{BW}, 42 \mathrm{~d} \mathrm{BW}$, and $70 \mathrm{~d}$ BW at a $5 \%$ genome-wise level were located at $351 \mathrm{cM}, 353 \mathrm{cM}$, and $360 \mathrm{cM}$, respectively. QTL for $49 \mathrm{~d} \mathrm{BW}$ at a suggestive level was located at $360 \mathrm{cM}$. QTL flanking markers, confidence intervals and the estimated location relative to the first marker on GGA1 are presented in Table IV. Means and standard errors (SE) of estimated additive and dominance effects, as well as each QTL contribution to the phenotypic variance are also presented in Table IV.

\subsection{QTL for fat traits}

The overall means and standard deviations (SD) of fat traits are presented in Table III. Among all the traits, a QTL for abdominal fat weight at a $1 \%$ genome-wise level was located at $205 \mathrm{cM}$. A QTL for fat thickness under the skin at a suggestive level was located at $265 \mathrm{cM}$. Two QTL for abdominal fat rate, and fat width at a $5 \%$ genome-wise level were located at $221 \mathrm{cM}$, and $72 \mathrm{cM}$, respectively. QTL flanking markers, confidence intervals and the estimated location relative to the first marker on GGA1 are presented in Table IV. 
Table II. Information of the 28 SNP.

\begin{tabular}{|c|c|c|c|c|c|c|}
\hline Marker no. & SNP & $\begin{array}{l}\text { Genetic } \\
\text { marker }^{1}\end{array}$ & $\begin{array}{c}\text { Physical } \\
\text { distance }(\mathrm{Mb})^{2}\end{array}$ & $\begin{array}{c}\text { Genetic } \\
\text { distance }(\mathrm{cM})^{3}\end{array}$ & Variations & Reases $^{4}$ \\
\hline M1 & rs 15197960 & ACW0388 & 10.39 & 0.00 & $\mathrm{G} / \mathrm{T}$ & TaqI \\
\hline M2 & rs13835792 & LEI0209 & 17.51 & 15.3 & $\mathrm{~T} / \mathrm{C}$ & Hin6I \\
\hline M3 & rs 15217588 & LEI0194 & 24.51 & 37.16 & $\mathrm{~A} / \mathrm{G}$ & MSPI \\
\hline M4 & rs13849344 & ADL351 & 31.22 & & $\mathrm{~A} / \mathrm{G}$ & Eoc721 \\
\hline M5 & rs 15245077 & ADL0019 & 37.17 & 76.72 & $\mathrm{~T} / \mathrm{C}$ & TaqI \\
\hline M6 & rs 13651060 & ADL307 & 42.70 & 94.08 & $\mathrm{~A} / \mathrm{G}$ & TaqI \\
\hline M7 & rs 15261060 & MCW0365 & 47.70 & 109.72 & $\mathrm{G} / \mathrm{T}$ & MSPI \\
\hline M8 & rs 15279778 & ACW0356 & 53.89 & 129.09 & $\mathrm{~T} / \mathrm{C}$ & MSPI \\
\hline M9 & rs 14837036 & MCW0112 & 61.19 & 165.13 & $\mathrm{~A} / \mathrm{G}$ & MSPI \\
\hline M10 & rs 15310568 & ACW0067 & 66.83 & 194.58 & $\mathrm{~T} / \mathrm{C}$ & MSPI \\
\hline M11 & rs 14848790 & LEI0101 & 75.21 & 215.8 & $\mathrm{~T} / \mathrm{C}$ & TaqI \\
\hline M12 & rs 13896190 & ADL251 & 79.39 & 228.88 & $\mathrm{~A} / \mathrm{G}$ & MSPI \\
\hline M13 & rs 15343813 & ADL0020 & 84.11 & 243.64 & $\mathrm{C} / \mathrm{T}$ & HaeIII \\
\hline M14 & rs15361441 & LEI0160 & 94.58 & 276.4 & $\mathrm{~T} / \mathrm{C}$ & Hin6I \\
\hline M15 & rs 14870625 & MCW200 & 100.75 & 295.71 & $\mathrm{~A} / \mathrm{G}$ & TaqI \\
\hline M16 & rs15389943 & ADL148 & 106.68 & 314.26 & $\mathrm{~A} / \mathrm{G}$ & HinPII \\
\hline M17 & rs 15397270 & ADL313 & 110.78 & 327.09 & $\mathrm{G} / \mathrm{T}$ & TaqI \\
\hline M18 & rs 14884316 & LEI0139 & 118.00 & 349.68 & $\mathrm{~A} / \mathrm{G}$ & NaeI \\
\hline M19 & rs 14889388 & ACW0254 & 125.11 & 371.93 & $\mathrm{~A} / \mathrm{G}$ & TaqI \\
\hline M20 & rs 14893213 & MCW0049 & 129.56 & 385.85 & $\mathrm{G} / \mathrm{C}$ & Hin6I \\
\hline M21 & rs 15462582 & MCW0102 & 142.30 & 425.72 & $\mathrm{~T} / \mathrm{C}$ & Hin6I \\
\hline M22 & rs 15468665 & LEI0084 & 147.57 & 442.2 & $\mathrm{~T} / \mathrm{C}$ & MSPI \\
\hline M23 & rs 15481358 & LEI0264 & 153.55 & 460.91 & $\mathrm{C} / \mathrm{G}$ & TaqI \\
\hline M24 & rs 14915286 & RBsts1 & 160.30 & 482.04 & $\mathrm{~A} / \mathrm{G}$ & AluI \\
\hline M25 & rs 15503250 & ACW0295 & 163.37 & 491.64 & $\mathrm{~A} / \mathrm{G}$ & HaeIII \\
\hline M26 & rs 15520693 & Ros0025 & 170.18 & 512.95 & $\mathrm{~A} / \mathrm{G}$ & TaqI \\
\hline M27 & rs 15538603 & ADL001 & 177.54 & 535.98 & $\mathrm{~A} / \mathrm{G}$ & Hin6I \\
\hline M28 & rs 15551556 & LEI0331 & 184.9 & & $\mathrm{~A} / \mathrm{T}$ & AluI \\
\hline
\end{tabular}

${ }^{1}$ The most adjacent microsatellite marker or STS marker to this SNP.

2 The physical distance of this SNP on GGA1.

${ }^{3}$ The genetic distance of this SNP identified by Cri-Map.

${ }^{4}$ Restriction endonucleases.

Means and standard errors (SE) of estimated additive and dominance effects, as well as each QTL contribution to the phenotypic variance are also given in Table IV.

\section{DISCUSSION}

In the present study, three significant QTL for $35 \mathrm{~d} \mathrm{BW}, 42 \mathrm{~d} \mathrm{BW}$ and $70 \mathrm{~d}$ BW were identified on GGA1, which were located at $351 \mathrm{cM}, 353 \mathrm{cM}$, 
Table III. Phenotypic observation and analysis of the F2 population.

\begin{tabular}{|c|c|c|c|c|c|}
\hline & & Mean & Max. & Min. & $\mathrm{SD}^{1}$ \\
\hline \multirow{14}{*}{ Growth traits } & 7d BW (g) & 58.80 & 85.11 & 33.90 & 8.41 \\
\hline & 14 d BW (g) & 123.38 & 178.20 & 70.90 & 18.40 \\
\hline & 21 d BW (g) & 210.83 & 304.90 & 101.62 & 33.77 \\
\hline & 28 d BW (g) & 311.83 & 448.80 & 119.30 & 50.09 \\
\hline & 35 d BW (g) & 437.02 & 628.80 & 142.00 & 75.78 \\
\hline & 42 d BW (g) & 574.06 & 888.20 & 214.3 & 104.71 \\
\hline & 49 d BW (g) & 708.11 & 1152.10 & 268.5 & 133.24 \\
\hline & $56 \mathrm{~d}$ BW (g) & 864.36 & 1422.00 & 430.00 & 153.23 \\
\hline & 63 d BW (g) & 1025.3 & 1572.00 & 490.50 & 190.50 \\
\hline & 70 d BW (g) & 1138.70 & 1900.00 & 699.00 & 214.32 \\
\hline & 77 d BW (g) & 1333.10 & 2150.00 & 797.30 & 249.24 \\
\hline & 84 d BW (g) & 1503.17 & 2800.00 & 804.00 & 296.76 \\
\hline & BWG1 (g) & 10.06 & 14.86 & 3.050 & 1.80 \\
\hline & BWG2 (g) & 19.77 & 36.14 & 10.10 & 4.24 \\
\hline \multirow{4}{*}{ Fat traits } & Fat thickness under skin (mm) & 3.95 & 9.00 & 0.05 & 1.47 \\
\hline & Fat width $(\mathrm{mm})$ & 11.83 & 22.97 & 2.00 & 3.42 \\
\hline & Abdominal fat weight $(\mathrm{g})$ & 27.60 & 94.40 & 2.60 & 16.73 \\
\hline & Abdominal fat rate (\%) & 2.07 & 6.38 & 0.18 & 1.23 \\
\hline
\end{tabular}

${ }^{1} \mathrm{n}=488$.

and $360 \mathrm{cM}$, respectively. The contribution of three QTL to phenotype variance ranged from $2.5-7.5 \%$. The contribution of a suggestive QTL for $49 \mathrm{~d}$ BW located at $360 \mathrm{cM}$ to phenotype variance was $3.0 \%$. When comparing the test statistics for these BW QTL, we found that two QTL curves for $35 \mathrm{~d} \mathrm{BW}$ and $42 \mathrm{~d}$ BW almost overlapped, and two QTL curves for $49 \mathrm{~d} \mathrm{BW}$ and $70 \mathrm{~d}$ BW almost overlapped too (Fig. 2). The additive effects of these QTL were both positive, and the dominant effects were both negative. This strongly suggests the action of one single QTL affecting growth throughout the growth period. An association test indicates that polymorphism of M19 was associated with $35 \mathrm{~d} \mathrm{BW}(P=0.022)$ and $42 \mathrm{~d} \mathrm{BW}(P=0.0025)$, polymorphism of M20 was associated with $70 \mathrm{~d}$ BW $(P=0.0487)$. From the analysis of marker genotypes, we could not infer what line the effects of the allele originate from.

Numerous studies demonstrated that QTL displaying significant linkage with BW are located on GGA1 [1,2,11,20,22,23]. Sewalem et al. performed a 


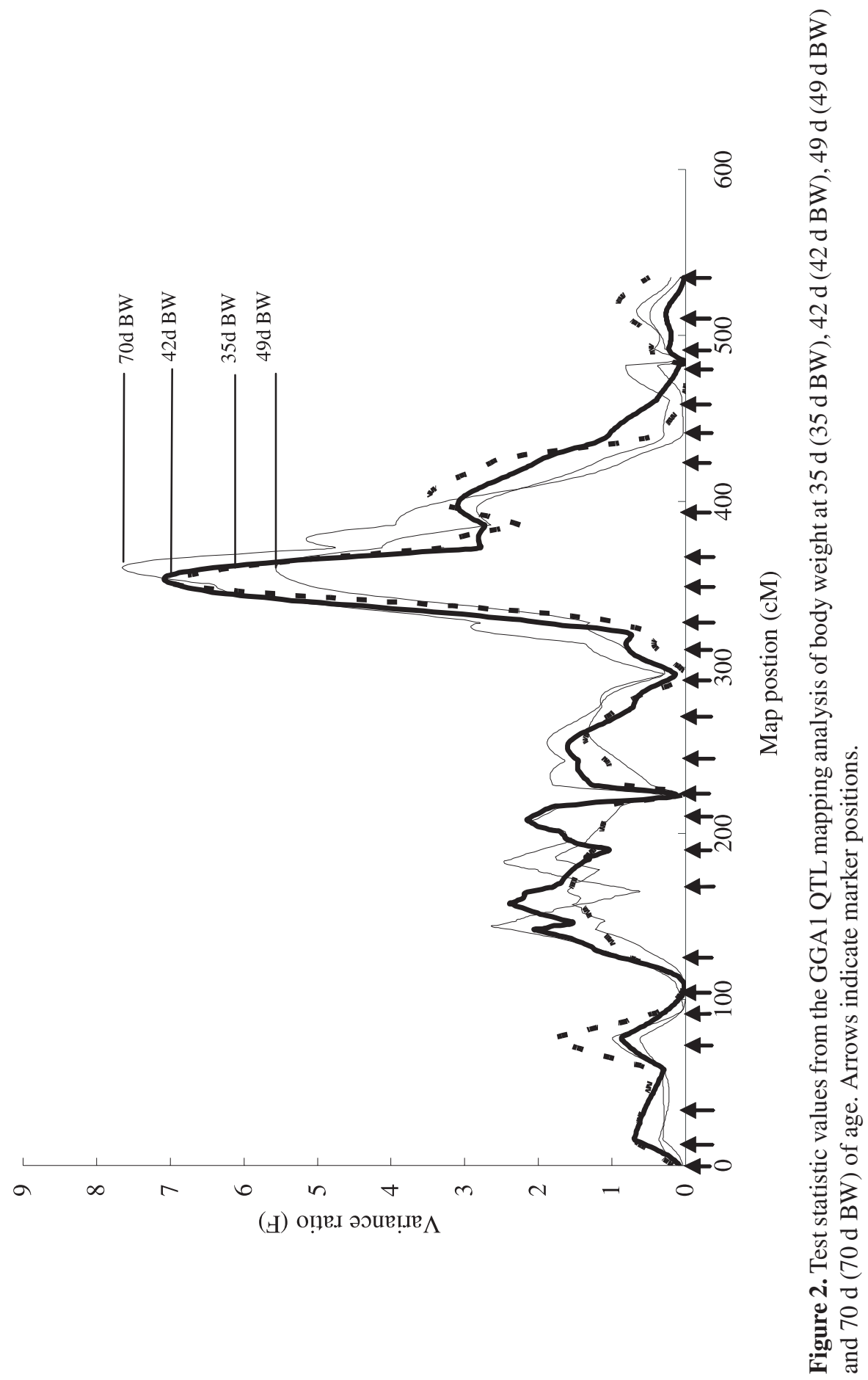


Table IV. Information of 8 QTL.

\begin{tabular}{|c|c|c|c|c|c|c|c|}
\hline Traits & F-ratio ${ }^{a}$ & $\begin{array}{l}\text { Position } \\
(\mathrm{cM})^{\mathrm{b}}\end{array}$ & Flanking-marker & $\begin{array}{r}\text { Additive } \\
\pm \mathrm{SE}\end{array}$ & $\begin{array}{r}\text { Dominance } \\
\pm \mathrm{SE}\end{array}$ & $\begin{array}{c}95 \% \\
\text { confidence } \\
\text { interval }\end{array}$ & Effects $^{\mathrm{c}}$ \\
\hline $35 \mathrm{~d} \mathrm{BW}$ & $6.98^{*}$ & 351 & LEI0160-MCW0102 & $29.36 \pm 11.33$ & $-112.36 \pm 30.44$ & 288-397 & $7.5 \%$ \\
\hline $42 \mathrm{~d} \mathrm{BW}$ & $7.08 *$ & 353 & ADL313-MCW0102 & $23.55 \pm 14.10$ & $-152.44 \pm 41.76$ & $335-419$ & $2.5 \%$ \\
\hline $49 \mathrm{~d} \mathrm{BW}$ & $5.57^{+}$ & 360 & ADL148-LEI0084 & $32.46 \pm 13.75$ & $-180.53 \pm 60.53$ & $317-430$ & $3.0 \%$ \\
\hline $70 \mathrm{~d} \mathrm{BW}$ & $7.65^{*}$ & 360 & ADL148-MCW0102 & $53.16 \pm 26.47$ & $-287.60 \pm 64.28$ & 319-391 & $3.1 \%$ \\
\hline $\begin{array}{l}\text { Fat } \\
\text { thickness } \\
\text { under } \\
\text { skin }\end{array}$ & $5.05^{+}$ & 265 & ACW0388-MCW0102 & $-0.573 \pm 0.54$ & $-0.329 \pm 0.15$ & $0-393$ & $7.6 \%$ \\
\hline Fat width & $7.44 *$ & 72 & ACW0388-ADL0020 & $1.563 \pm 0.27$ & $6.26 \pm 0.862$ & $0-239$ & $10.4 \%$ \\
\hline $\begin{array}{l}\text { Abdominal } \\
\text { fat weight }\end{array}$ & $10.74 * *$ & 205 & ACW0356-LEI0160 & $-3.612 \pm 1.22$ & $-14.26 \pm 4.351$ & $136-265$ & $2.3 \%$ \\
\hline $\begin{array}{l}\text { Abdominal } \\
\text { fat rate }\end{array}$ & $8.46^{*}$ & 221 & MCW0112-MCW200 & $-0.426 \pm 0.17$ & $-0.77 \pm 0.27$ & $168-283$ & $6.0 \%$ \\
\hline
\end{tabular}

${ }^{a}+$ Suggestive linkage; $*$ genome-wise linkage at $5 \% ; * *$ genome-wise linkage at $1 \%$.

${ }^{\mathrm{b}}$ Position of QTL relative to the first marker in the set for this chromosome (Tab. II).

${ }^{\mathrm{c}}$ Percentage of total phenotypic variance explained by this QTL.

genome scan for growth using a crossing between a White Leghorn line and a commercial broiler sire line. Two significant QTL for $3 \mathrm{wk}-\mathrm{BW}$ were located on GGA1 at $145 \mathrm{cM}$, and $481 \mathrm{cM}$, respectively, in which $95 \%$ confidence intervals were 113-217 cM, and 441-526 cM, respectively. Another significant QTL for 9 wk-BW was located on GGA1 at $414 \mathrm{cM}$ with 34-419 cM of the $95 \%$ confidence interval [20]. Van Kaam et al. performed a genome scan for growth and carcass composition using a crossing population between two broiler lines. Only one QTL was up to a genome-wide significant level. This growth QTL was located on GGA1 at $235 \mathrm{cM}$ [23]. Tatsuda et al. identified two significant QTL for growth using a crossing population between a Satsumadori line and a White Plymouth Rock line. One QTL identified on GGA1 was located at $220 \mathrm{cM}$ [22]. Kerje et al. identified two major QTL for growth, which were located on GGA1 using a crossing population between Red Jungle Fowl (RJF) and White Leghorn. The two major QTL for growth were located around positions $68 \mathrm{cM}$ and $416 \mathrm{cM}$, which had a large effect on growth from $7 \mathrm{~d}$ of age on and during the entire growth period. In addition, this explained more than $20 \%$ of the residual phenotypic variance for adult body weight, and about $35 \%$ of the difference in adult size between the two populations [11]. Nones et al. selected 26 microsatellite markers to conduct a scan on GGA1. 
They identified a significant QTL for $35 \mathrm{~d}$ BW and $42 \mathrm{~d}$ BW, which was located at $332 \mathrm{cM}$ of GGA1 (LEI0079-MCW0145) [15]. The QTL interval almost overlapped a QTL interval (LEI0160-MCW0102) determined in the present study. Interestingly, another significant QTL for $46 \mathrm{~d} \mathrm{BW}, 112 \mathrm{~d}$ BW and $200 \mathrm{~d}$ BW was reported at a similar position on GGA1 from a crossing population between RJF and White Leghorn, which was located at $337 \mathrm{cM}$ [1].

Fatness is being focused on in the QTL mapping studies of chickens. Iekobi et al. scanned the whole chicken genome for QTL controlling fat traits in a resource population derived from a crossing between a broiler line and layer line. Four QTL affecting abdominal fat weight were identified on GGA3, 7, 15 , and 28, respectively, and another four QTL for abdominal fat rate were identified on GGA1, 5, 7, and 28, respectively. A QTL for abdominal fat rate identified on GGA1 was located at $126 \mathrm{cM}$, in which the confidence interval was $100-182 \mathrm{cM}$. Another QTL for skin fat weight was located at $454 \mathrm{cM}$ of GGA1, in which the confidence interval was 333-487 cM [8]. Jenen et al. identified two QTL for fat traits located on GGA1 in a crossing population between two genetically different outcross broiler dam lines, which originated from the White Plymouth Rock breed. They found that a significant QTL controlling abdominal fat rate at $70 \mathrm{~d}$ of age was located at $241 \mathrm{cM}$ (MCW0058-MCW0101), and a suggestive QTL for abdominal fat weight at $70 \mathrm{~d}$ of age was located at $214 \mathrm{cM}$ (LE10174-ADL0361) [10]. Nones et al. [15] also reported a QTL for abdominal fat weight located on GGA1 at $194 \mathrm{cM}$ (ADL0020-LEI0160). In the present study, we identified four QTL for fat traits, a significant QTL at a $1 \%$ genome-wise level for abdominal fat weight, two significant QTL at a 5\% genome-wise level for abdominal fat rate and fat width, and a suggestive QTL for fat thickness under the skin. Each QTL explained the phenotypic variance with a range of 2.3-10.4\%. A QTL for abdominal fat weight and a QTL for abdominal fat rate appear to be very consistent with what has been reported by Jenen $e t a l$. and Nones et al. Fat deposition in chickens has commanded a great deal of interest over the years because of the nutritional significance of fat to humans. Measuring abdominal and skin fat content is expensive and the availability of QTL for use in breeding practice would therefore prove to be of great value.

Confirmation of the presence and location of the QTL of interest can be achieved by comparing the results from different QTL studies. In the study of two distinct layer $\times$ layer crossings, Siwek et al. validated the presence of a QTL for the primary antibody response to keyhole lympet hemocyanin on GGA14 in both populations [21]. In the present study, we confirmed a QTL for chicken growth, a QTL for abdominal fat weight and a QTL for abdominal 
fat rate with SNP mapping. We also detected two novel QTL for fat thickness under the skin, and fat width, respectively. In the above earlier studies, different breeds, different markers and measurements were used. This implies that these regions surely harboured QTL affecting these traits and deserve to be further explored.

\section{ACKNOWLEDGEMENTS}

This work was funded by projects under the Major State Basic Research Development Program, China, project no. 2006CB102100. The authors would like to acknowledge Ms. Danlin He and Mr. Zhijun Peng for their technical assistance in building up the F2 resource population, and the two referees for their comments on this manuscript.

\section{REFERENCES}

[1] Carlborg O., Kerje S., Schutz K., Jacobsson L., Jensen P., Andersson L., A global search reveals epistatic interaction between QTL for early growth in the chicken, Genome Res. 13 (2003) 413-421.

[2] Carlborg O., Hocking P.M., Burt D.W., Haley C.S., Simultaneous mapping of epistatic QTL in chickens reveals clusters of QTL pairs with similar genetic effects on growth, Genet. Res. 83 (2004) 197-209.

[3] Churchill G.A., Doerge R.W., Empirical threshold values for quantitative trait mapping, Genetics 138 (1994) 963-971.

[4] Fitzpatrick E., Goring H.H., Liu H., Borg A., Forrest S., Cooper D.W., Brennecke S.P., Moses E.K., Fine mapping and SNP analysis of positional candidates at the preeclampsia susceptibility locus (PREG1) on chromosome 2, Hum. Biol. 76 (2004) 849-862.

[5] Green P., Falls K., Crooks S., Documentation for CRIMAP. Version 2.4., Washington School of Medicine, St. Louis, MO, 1990.

[6] Groenen M.A., Cheng H.H., Bumstead N., Benkel B.F., Briles W.E., Burke T., Burt D.W., Crittenden L.B., Dodgson J., Hillel J., Lamont S., de Leon A.P., Soller M., Takahashi H., Vignal A., A consensus linkage map of the chicken genome, Genome Res. 10 (2000) 137-147.

[7] Haley C.S., Knott S.A., Elsen J.M., Mapping quantitative trait loci in crosses between outbred lines using least squares, Genetics 136 (1994) 1195-1207.

[8] Ikeobi C.O., Woolliams J.A., Morrice D.R., Law A., Windsor D., Burt D.W., Hocking P.M., Quantitative trait loci affecting fatness in the chicken, Anim. Genet. 33 (2002) 428-435. 
[9] International Chicken Genome Sequencing Consortium, Sequence and comparative analysis of the chicken genome provide unique perspectives on vertebrate evolution, Nature 432 (2004) 695-716.

[10] Jennen D.G., Vereijken A.L., Bovenhuis H., Crooijmans R.M., van der Poel J.J., Groenen M.A., Confirmation of quantitative trait loci affecting fatness in chickens, Genet. Sel. Evol. 37 (2005) 215-228.

[11] Kerje S., Carlborg O., Jacobsson L., Schutz K., Hartmann C., Jensen P., Andersson L., The twofold difference in adult size between the red jungle fowl and White Leghorn chickens is largely explained by a limited number of QTLs, Anim. Genet. 34 (2003) 264-274.

[12] Knott S.A., Marklund L., Haley C.S., Andersson K., Davies W., Ellegren H., Fredholm M., Hansson I., Hoyheim B., Lundstrom K., Moller M., Andersson L., Multiple marker mapping of quantitative trait loci in a cross between outbred wild boar and large white pigs, Genetics 149 (1998) 1069-1080.

[13] Lander E., Kruglyak L., Genetic dissection of complex traits: guidelines for interpreting and reporting linkage results, Nat. Genet. 11 (1995) 241-247.

[14] Meaburn E., Butcher L.M., Schalkwyk L.C., Plomin R., Genotyping pooled DNA using 100K SNP microarrays: a step towards genomewide association scans, Nucleic Acids Res. 34 (2006) e27.

[15] Nones K., Ledur M.C., Ruy D.C., Baron E.E., Melo C.M., Moura A.S., Zanella E.L., Burt D.W., Coutinho L.L., Mapping QTLs on chicken chromosome 1 for performance and carcass traits in a broiler $\times$ layer cross, Anim. Genet. 37 (2005) 95-100.

[16] Ober C., Abney M., McPeek M.S., The genetic dissection of complex traits in a founder population, Am. J. Hum. Genet. 69 (2001) 1068-1079.

[17] Ponsuksili S., Murani E., Schellander K., Schwerin M., Wimmers K., Identification of functional candidate genes for body composition by expression analyses and evidencing impact by association analysis and mapping, Biochim. Biophys. Acta 1730 (2005) 31-40.

[18] Posthuma D., Beem A.L., de Geus E.J., van Baal G.C., von Hjelmborg J.B., Iachine I., Boomsma D.I., Theory and practice in quantitative genetics, Twin Res. 6 (2003) 361-376.

[19] Seaton G., Haley C.S., Knott S.A., Kearsey M., Visscher P.M., QTL express, 2001, http://qtl.cap.ed.ac.uk.

[20] Sewalem A., Morrice D.M., Law A., Windsor D., Haley C.S., Ikeobi C.O., Burt D.W., Hocking P.M., Mapping of quantitative trait loci for body weight at three, six, and nine weeks of age in a broiler layer cross, Poult. Sci. 81 (2002) 1775-1781.

[21] Siwek M., Buitenhuis A.J., Cornelissen S.J.B., Nieuwland M.G.B., Bovenhuis H., Crooijmans R.P., Groenen M.A., de Vries-Reilingh G., Parmentier H.K., van der Poel J.J., Detection of different QTL for antibody responses to keyhole lympet hemocyanin and Mycobacterium butyricum in two unrelated populations of laying hens, Poult. Sci. 82 (2003) 1845-1852.

[22] Tatsuda K., Fujinaka K., Genetic mapping of the QTL affecting body weight in chickens using a F2 family, Br. Poult. Sci. 42 (2001) 333-337. 
[23] Van Kaam J.B.C.H.M., Groenen M.A.M., Bovenhuis H., Veenendaal A., Vereijken A.L.J., van Arendonk J.A.M., Whole genome scan in chickens for quantitative trait loci affecting growth and feed efficiency, Poult. Sci. 78 (1999) 15-23.

[24] Visscher P.M., Thompson R., Haley C.S., Confidence intervals in QTL mapping by bootstrapping, Genetics 143 (1996) 1013-1020.

[25] Wang J., He X., Ruan J., Dai M., Chen J., Zhang Y., Hu Y., Ye C., Li S., Cong L., Fang L., Liu B., Li S., Wang J., Burt D.W., Wong G.K., Yu J., Yang H., Wang J., Chick VD: a sequence variation database for the chicken genome, Nucleic Acids Res. 33 (2005) D438-D441.

[26] Wong G.K., Liu B., Wang J., Zhang Y., Yang X., Zhang Z., Meng Q., Zhou J., Li D. et al., International chicken polymorphism map consortium, A genetic variation map for chicken with 2.8 million single-nucleotide polymorphisms, Nature 432 (2004) 717-725. 